\title{
Magnetic Resonance Imaging of the Normal Stifle Joint in Buffaloes (Bos bubalis): An Anatomic Study
}

\author{
M.S. Sherif, M. Attia, H. Bahgaat and A. Kassab* \\ Department of Anatomy and Embryology, Faculty of Veterinary Medicine (Moshtohor), Benha University, Egypt
}

\begin{abstract}
This research has been conducted in order to describe the normal anatomical structures of the stifle joint in buffaloes (Bos bubalis) by using the magnetic resonance imaging and the corresponding anatomical sections. The anatomical slices were used to facilitate the interpretation of the MRI images, and therefore the diagnosis for stifle related diseases would be much easier. The hind limbs of ten healthy adult buffaloes (Twenty stifle joints) were used. After slaughtering, MR images were made in sagittal, transverse, and dorsal planes. After that, the limbs were sectioned by using an electric band saw according to the corresponding MRI images after freezing at $-20^{\circ}$ for 48 hours. Clinically relevant anatomic structures were identified and labeled at each level of the matching images (MR and anatomic slices).

MRI images were used to recognize the bony and soft tissue structures of the stifle joint. The articular cartilage appeared as line of hyperintensity which was separated from the subcondral bone by gray line (moderate signal intensity). It was difficult to differentiate between the synovia, infrapatellar fat body and the articular cartilage because of the similar hyperintensity. The meniscial, femoropatellar and cruciate ligaments were recognized as moderate signal intensity. The collateral ligaments and intermediate patellar ligaments, and the common tendon of the Mm. extensor digitorum longus and peroneus tertius, as well as, the menisci and the medial patellar fibrocartilage appeared as hypointense signal.
\end{abstract}

The knowledge of normal anatomy of the stifle joint would serve as initial reference and guide for the stifle diagnosis of the suspected buffaloes by using MRI technique.

Keywords: Anatomy, Buffalo, MRI, Stifle.

\section{INTRODUCTION}

Magnetic resonance Imaging (MRI) is widely used in the diagnosis of human musculoskeletal disease [1]. This may be due to the superior resolution of the MRI for the soft tissue structures and significant ability to take images in multiple planes.

Diseases of the stifle joint in the ruminants are common, especially in the buffalo. The stifle joint is usually exposed to many surgical problems as patellar luxation, gonitis (stifle arthritis), synovitis, fracture, meniscial tearing and cruciate ligament sprain in the bovine [2].

Many researches have been conducted in the bovine lameness because of its economic importance and for better understanding of the pathogenesis of the bovine stifle problems [3].

The bovine stifle has a complex structure in joints, ligaments and tendons [4]. Classical anatomic atlases don't provide the spectrum of views and the required details for the modern diagnostic and surgical techniques [5].

Magnetic resonance imaging (MRI) would give more additional information on soft tissue and osseous injuries for the bovine digits and hoof if it was compared by the current

*Address correspondence to this author at the Department of Anatomy and Embryology, Faculty of Veterinary Medicine, Benha University, Egypt; Tel: 0020132461411; Fax: 0020132460640; E-mail: kassab_aa@yahoo.com diagnostic imaging technique such as radiography and ultrasonography which provides limited information $[6,7]$. Furthermore, Tendons and ligaments are more distinguishable by MRI than computed tomography or ultrasonography $[8,9]$.

To date, the detailed comparative study of normal gross and MRI sections of the buffalo stifle has not been conducted yet. Therefore, this study will describe the normal anatomy of the stifle joint in buffaloes (Bos bubalis) for the magnetic resonance images and its correlated anatomical sections to facilitate the interpretation during the diagnosis.

\section{MATERIALS AND METHODS}

Animals- Twenty stifle joints of ten healthy buffaloes, 7 males and 3 females were used in this study. Their ages ranged from 10 - 17 months. The selected animals were subjected to clinical, radiographic and ultrasonographic examinations before slaughtering; no abnormalities were observed. Three animals were collected from the teaching farm at the Faculty of Veterinary Medicine and the Faculty of Agriculture at Benha University in Egypt, while other seven animals were obtained from Benha slaughterhouse. Immediately after slaughtering, limbs were cooled and imaged within 12 hours to minimize post-mortem changes.

MRI examination- SIGNA HDe 1.5 TGE MRI scanner was used to accomplish the Magnetic Resonance Imaging; by placing in a torso phased array coil ( 2 Tesla) for the sagittal and dorsal scans and in a body coil ( 2 Tesla) for the 
transverse scans, $5 \mathrm{~mm}$ slicing as indicated by Van der Straaten et al. [10]. Scanning details (as TR, TE and others) found in the MR images. Then, the MR images were reformatted with a software E-film.

After the MR images were obtained, the limbs articular capsule were distended by either red or blue colored gum milk latex according to Nickel et al. [11] and Dyce et al. [12] in ruminants. Immediately after injection, the joints were flexed and extended 100 times and frozen at $-20^{\circ}$. The limbs then were sectioned using an electric band saw, like the corresponding MR images. All sections were cleaned, photographed and kept for the future studies.

Comparison of $M R$ and anatomic images-Important anatomic structures were identified and labeled in the matched MR images and gross-sections of the buffalo stifle joint with the aid of multiple references [11, 13-15]. Ten photos from both MRI and gross sections were selected for publication. Some structures present in the anatomical sections could not be seen on the corresponding MR images and vice versa.

\section{RESULTS}

From the collection of matched MR and anatomical images, 3 representative sagittal combinations were selected (Figs. 1-3), 4 cross sections (Figs. 4-7), and 3 dorsal combinations (Figs. 8-10). On each MR image, a further two small photos were put in corners to clarify the main section level. On the anatomic slices, it was possible to identify all muscles, tendons, and ligaments surrounding the stifle joint.

The bone surfaces could be easily identified in all MR images. The compact bone appeared as hypointense signal, while spongy bone showed heterogenous signal intensity due to high fat content in the bone marrow and trabecular pattern. There was a regular and obviously distinct corticocancellous junction. The distal epiphysis of the femur and proximal diaphysis of the tibia ossification centers appeared as irregular line of homogenous hypointense signal. The articular cartilage appeared as line of hyperintensity which was separated from the subcondral bone by gray line (moderate signal intensity). The signal intensity of the articular cartilage was to some extent similar to synovia.

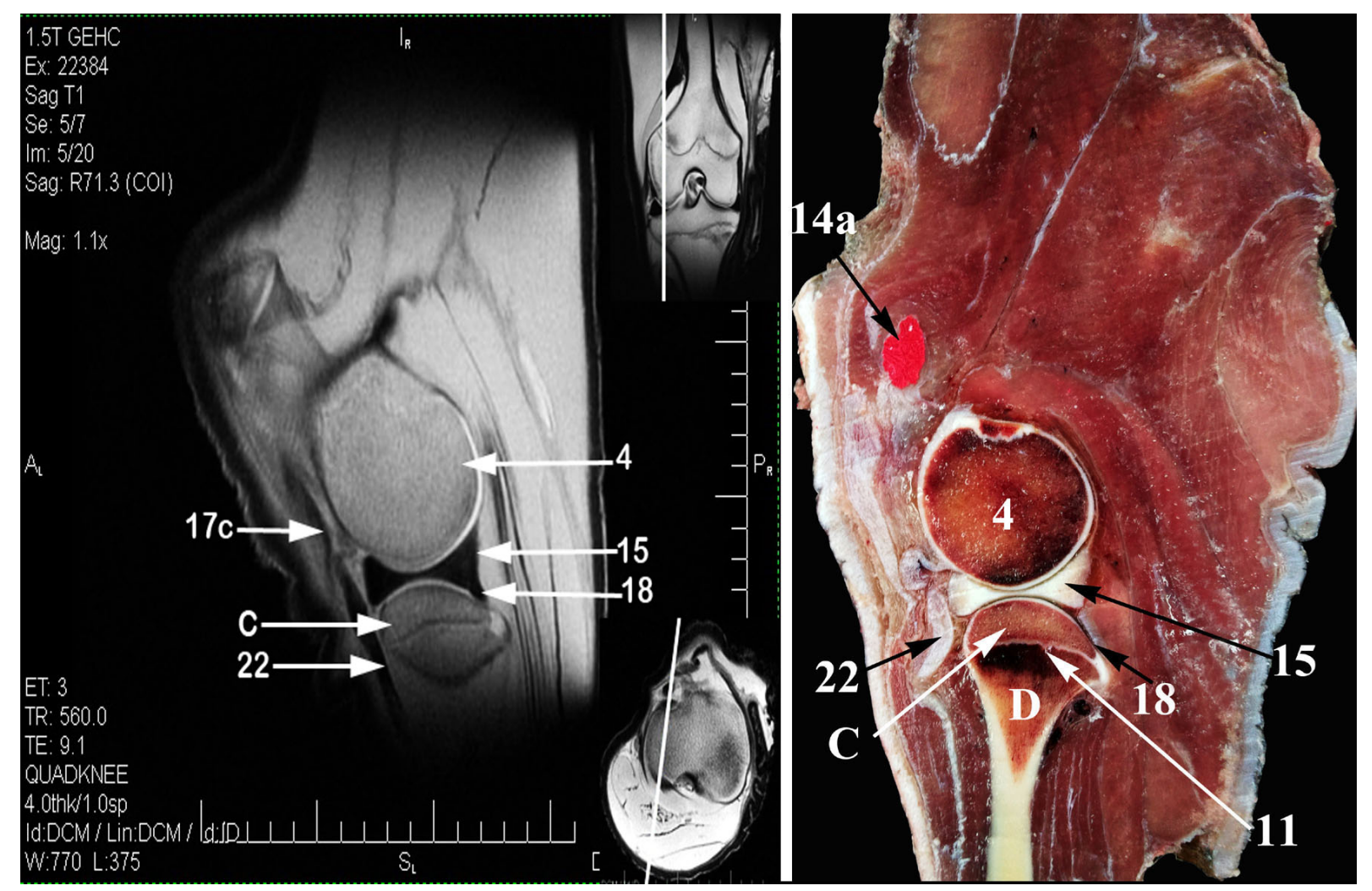

Fig. (1). Sagittal MR image (A) and gross anatomic section (B) of the left buffalo stifle at the level of $3 \mathrm{~cm}$ lateral to the Fossa intercondylaris (dorsal is up and caudal is to the right of the viewer). A, Corpus ossis femoris; B, Distal epiphysis of os femoris; C, Extremitas proximalis tibiae; D, Corpus tibiae; 1, Trochlea ossis femoris (1a, medial ridge; 1c, intertrochlear groove); 2, Facies popliteal; 3, Condylus medialis of os femoris; 4, Condylus lateralis of os femrois (4a, Fossa extensoria); 6, Patella (6a, Basis patellae; 6b, Processus cartilaginous; 6c, Apex patellae; 6d, Facies articularis; 6e, Facies cranialis); 7, Condylus lateralis of the tibia (7a, Incisura Poplitea); 8, Tuberositas tibiae; 9, Distal epiphysis of the femur ossification center; 10, Tibial tuberosity ossification center; 11 , Proximal diaphysis of the tibia ossification center; 12, medial femorotibial sac; 13, lateral femorotibial sac; 14, femoropatellar synovial sac (14a, proximal pouch); 15, Meniscus lateralis (15a, cranial meniscotibial ligament; 15b, Lig. Meniscofemorale); 16, Meniscus medialis (16a, cranial meniscotibial ligament); 17, Ligg. Cruciata genus (17a, Lig. cruciatum craniale; 17b, Lig. cruciatum caudale); 18, Lig. popliteum obliquum; 19, Fibrocartilagines parapatellaris medialis; 20a, Lig. patellae intermedium; 20b, Lig. patellae mediale; 20c, Lig. patellae laterale; 21, Corpus adiposum infrapatellare; 22, Common tendon of the extensor digitorum longus and peronaeus tertius; VM, M. vastus medialis; VI, M. vastus intermedius; GL, M. gastrocnemius (Caput laterale);GM, M. gastrocnemius (Caput mediale); SD, M. flexor digitorum superficialis; POP, M. popliteus; ST, M. semitendinosus; SM, M. semimembranosus. 

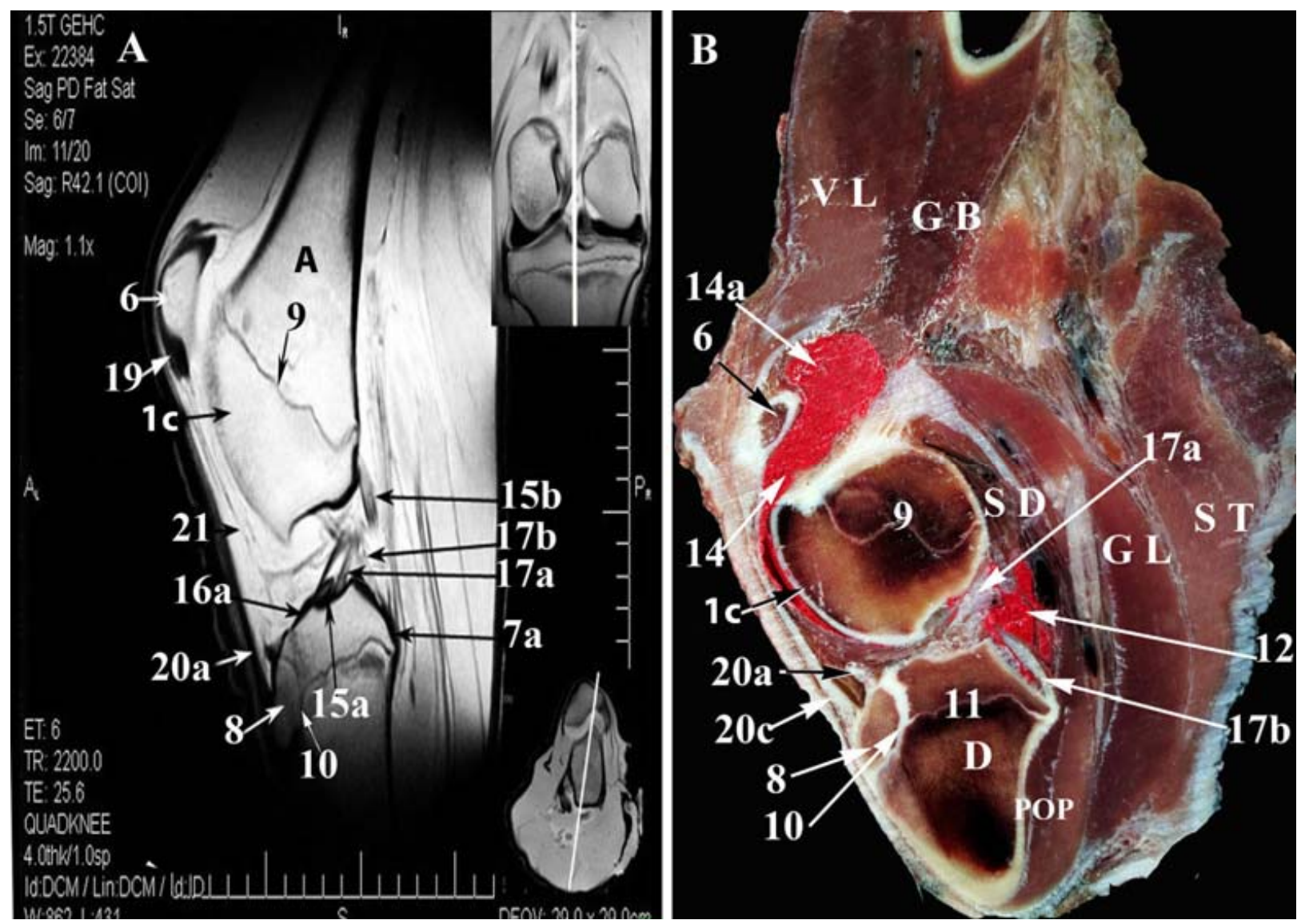

Fig. (2). Sagittal MR image (A) and anatomic section (B) of the left buffalo stifle at the middle of the Fossa intercondylaris (dorsal is up and caudal is to the right of the viewer). Abbreviations as previous.
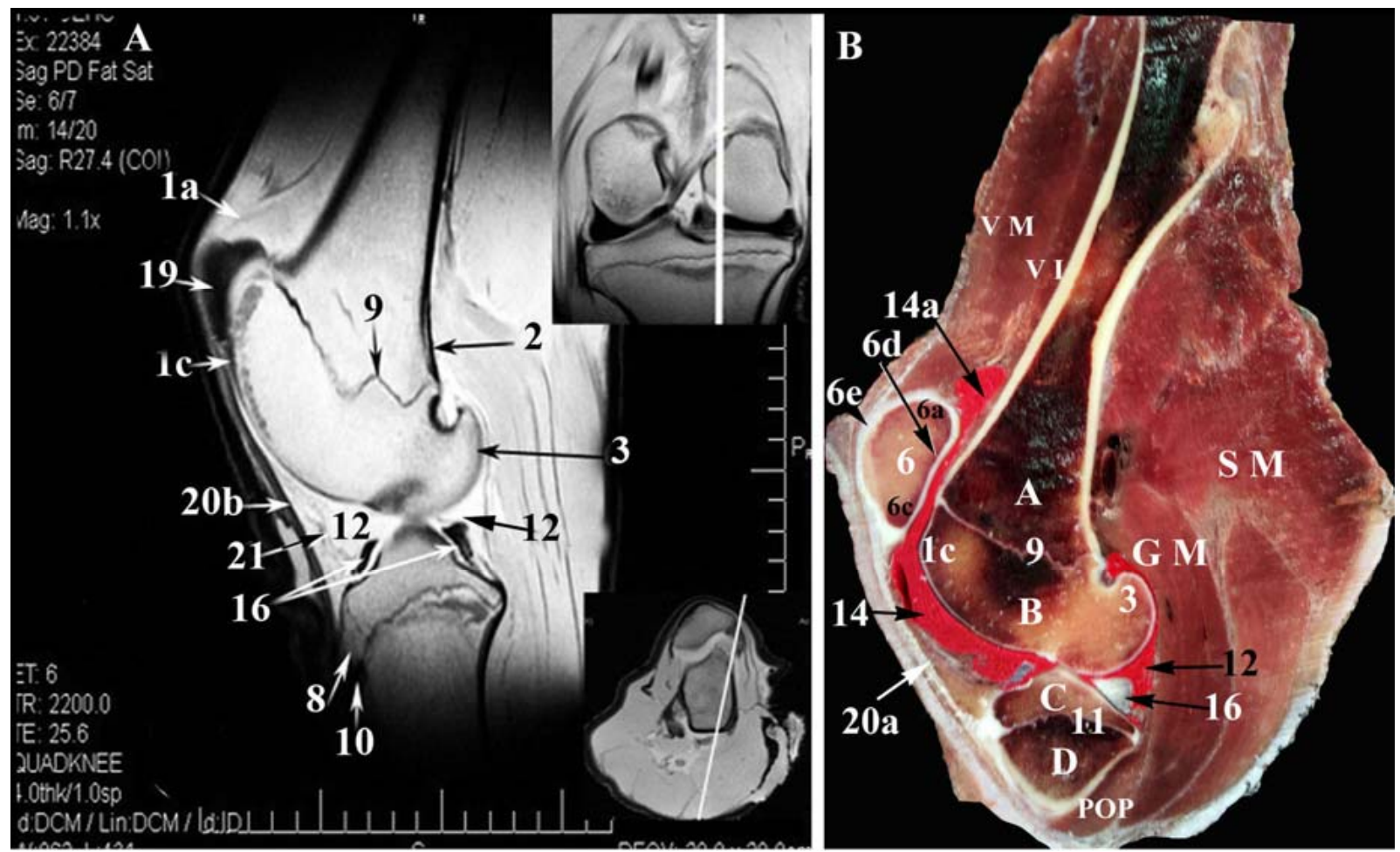

Fig. (3). Sagittal MR image (A) and gross anatomic section (B) of the right buffalo stifle at $1 \mathrm{~cm}$ medial to the fossa intercondylaris at the most lateral part of the Condylus medialis of the Os femoris (dorsal is up and caudal is to the right of the viewer). Abbreviations as previous. 

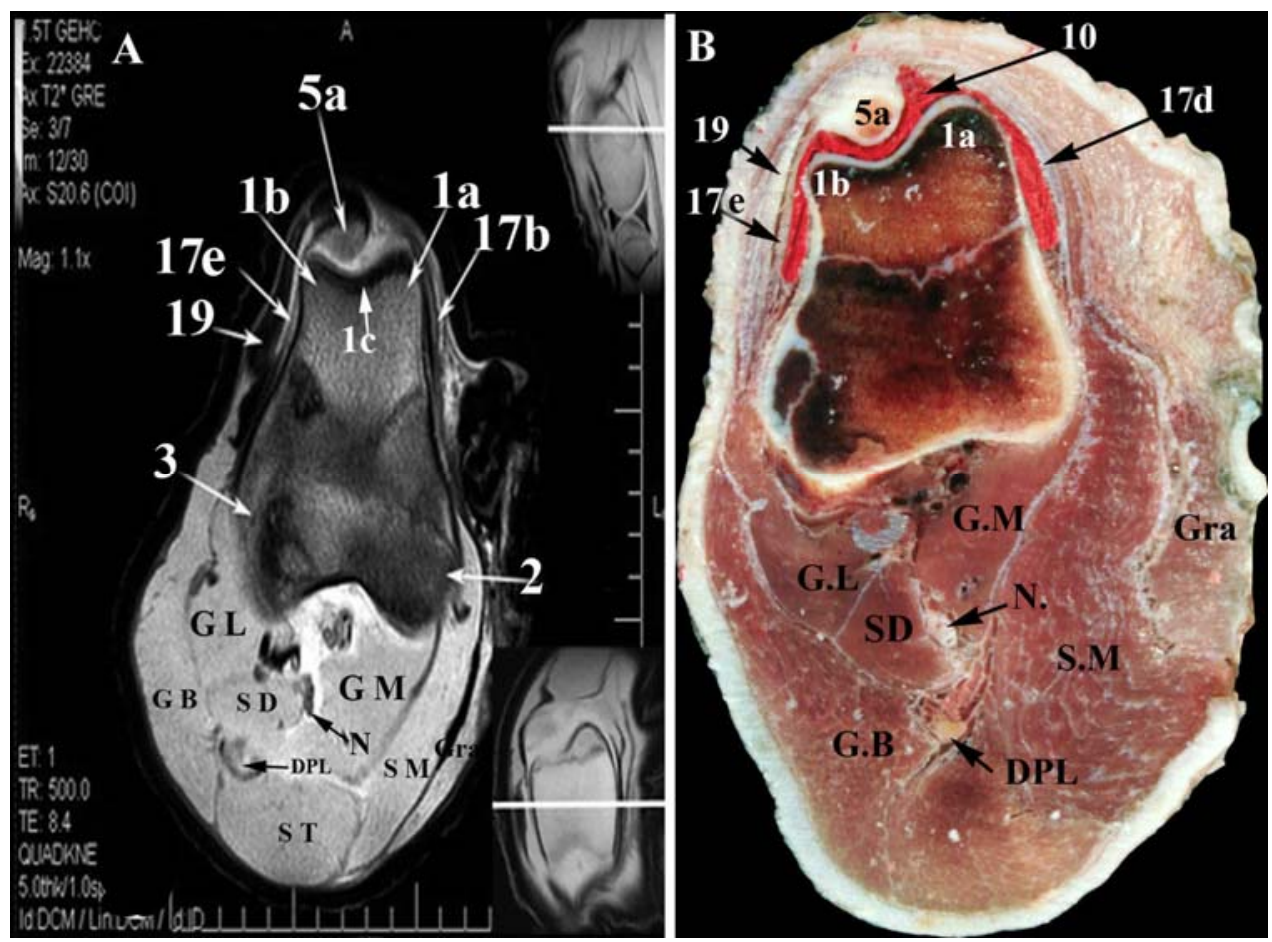

Fig. (4). Transverse MR image (A) and gross anatomic section (B) of the left buffalo stifle at the level of the patellar apex (dorsal is up and lateral is to the left of the viewer). 1, Trochlea ossis femoris (1a, medial ridge; 1b, lateral ridge; 1c, intertrochlear groove); 2, Condylus medialis of os femoris; 3, Condylus lateralis of os femoris; 3a, Fossa extensoria; 4, Fossa intercondylaris; 5a, Apex patellae; 6, Eminentia intercondylaris (6a, tuberculum intercondylare mediale; 6b, tuberculum intercondylare laterale); 9, medial femorotibial synovial sac; 10, femoropatellar synovial sac; 11, Meniscus Lateralis (11a, cranial meniscotibial ligament of the lateral meniscus; 11b, Lig. Meniscofemorale of the lateral meniscus); (12, Meniscus medialis (12a, cranial meniscotibial ligament; 12b, caudal meniscotibial ligament); 13a, Lig. cruciatum craniale; 13b, Lig. cruciatum caudale; 14, Lig. collaterale laterlae; 15, Lig. collaterale mediale; 16, Lig. popliteum obliquum; 17a, Lig. patellae intermedium; 17b, Lig. patellae mediale; 17c, Lig. patellae laterale; 17d, Lig. femoropatellare mediale; 17e, Lig. femoropatellare laterale; 18, Corpus adiposum infrapatellare; 19, Gluteobiceps tendon; 20, Common tendon of the extensor digitorum longus and peronaeus tertius; T, proximal Extremity of the tibia; DPL, Deep popliteal lymph node; GL, M. gastrocnemius (Caput laterale); GM, M. gastrocnemius (Caput mediale); SD, M. flexor digitorum superficialis; POP, M. popliteus; GB, M. gluteobiceps femoris; ST, M. semitendinosus; SM, M. semimembranosus; Gra, M. gracilis.

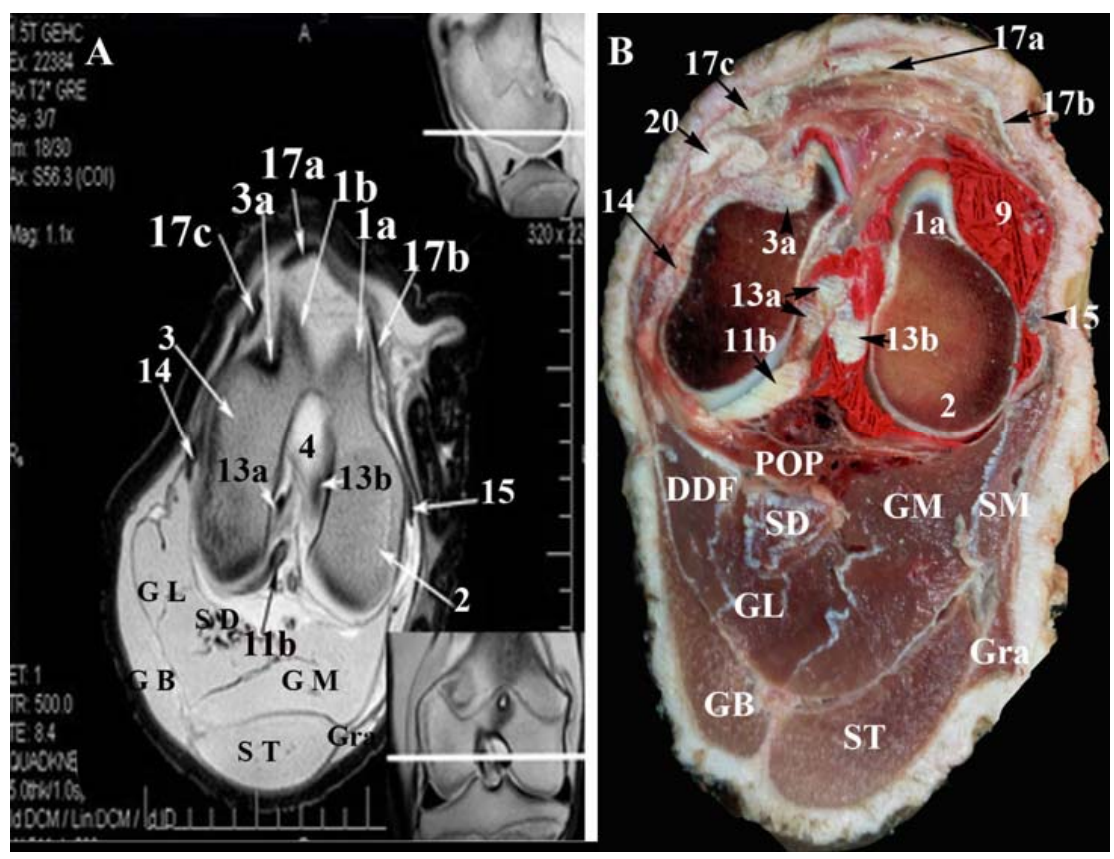

Fig. (5). Transverse MR image (A) and gross anatomic section (B) of the left buffalo stifle at the level of the proximal parts of the Eminentia intercondylaris (dorsal is up and lateral is to the left of the viewer). Abbreviations as previous. 


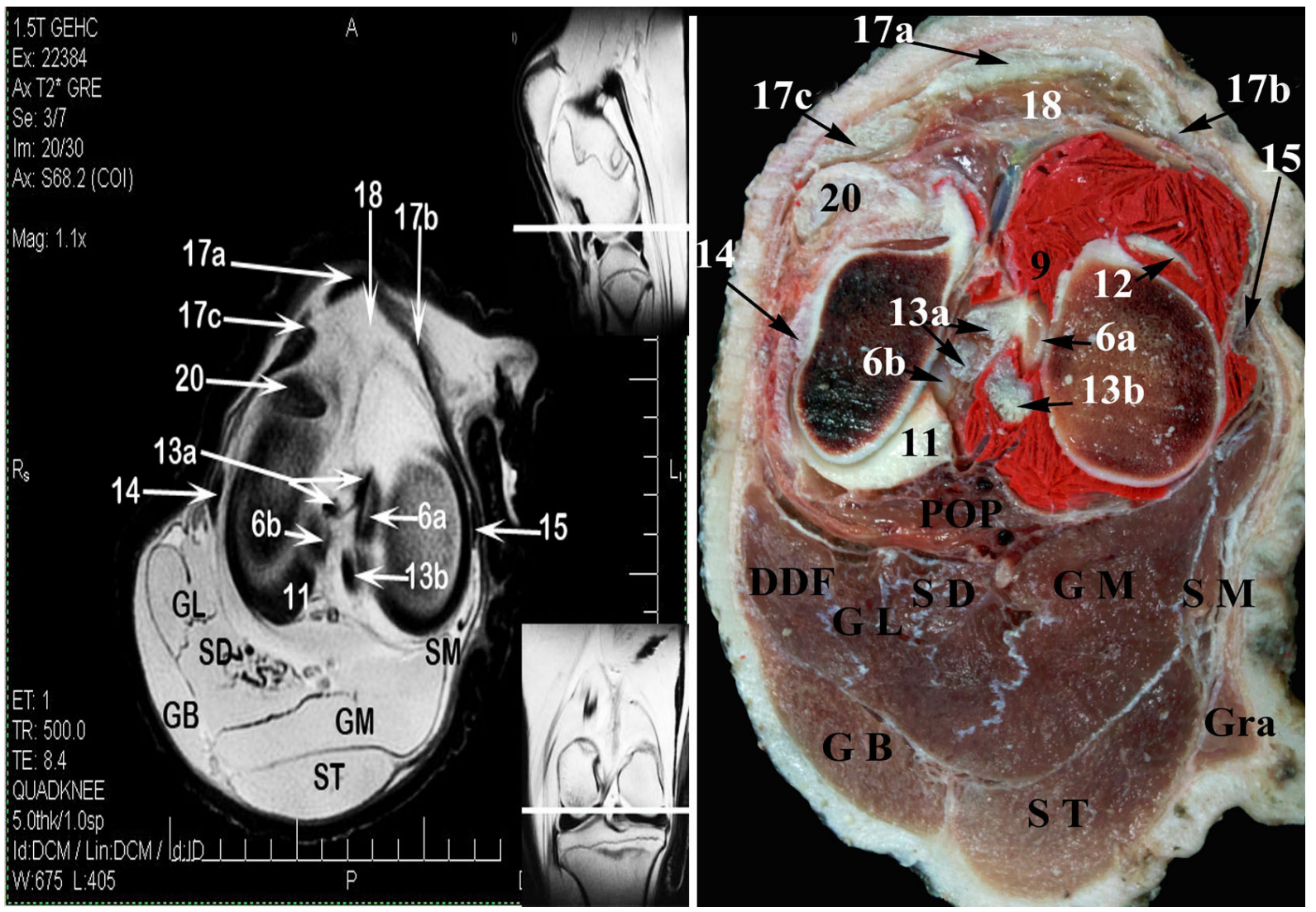

Fig. (6). Transverse MR image (A) and gross anatomic section (B) of the left buffalo stifle at the level the base of the Eminentia intercondylaris and most distal parts of the femoral condyles (dorsal is up and lateral is to the left of the viewer). Abbreviations as previous.
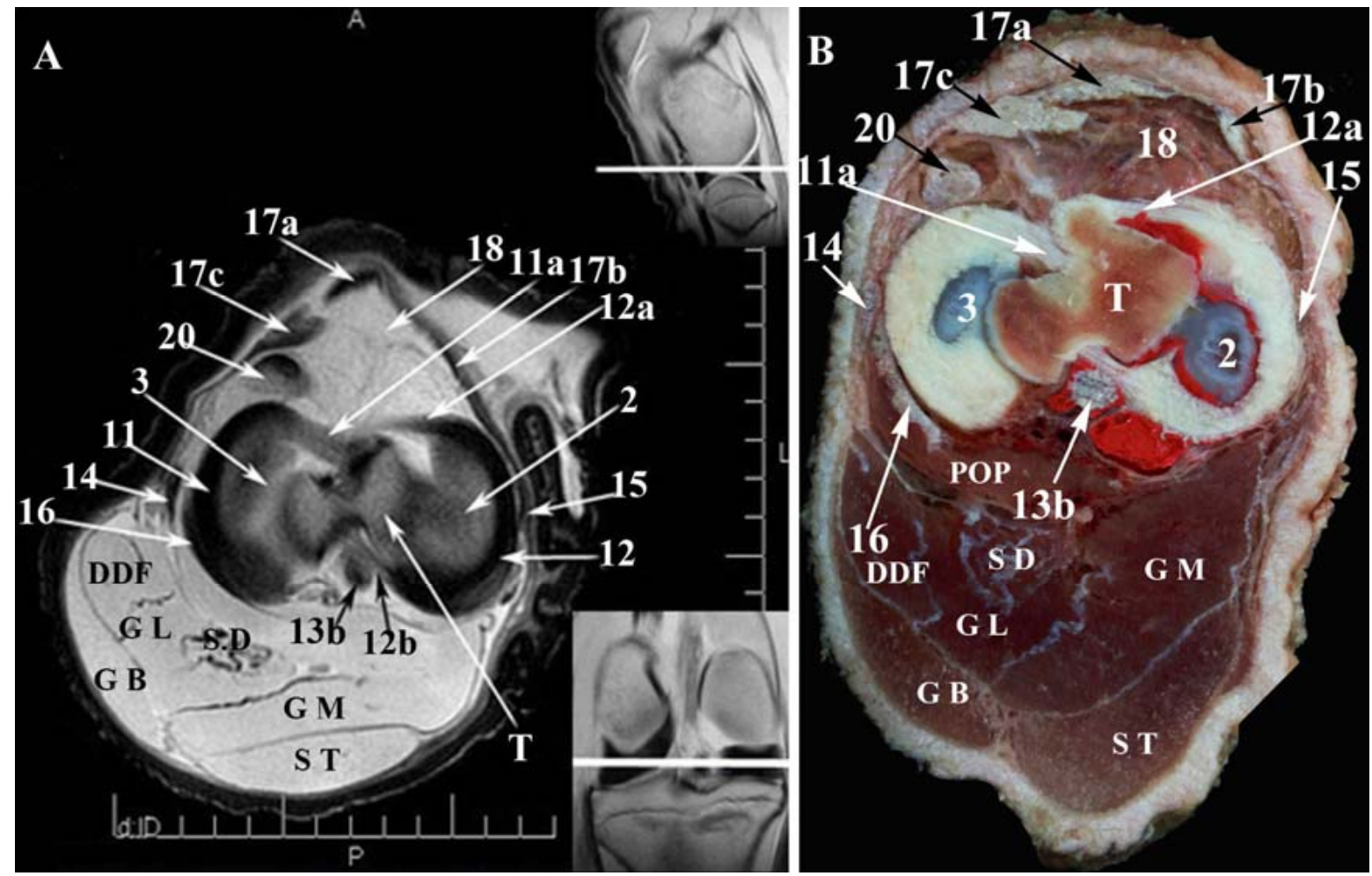

Fig. (7). Transverse MR image (A) and gross anatomic section (B) of the left buffalo stifle at the level of the menisci (dorsal is up and lateral is to the left of the viewer). Abbreviations as previous. 

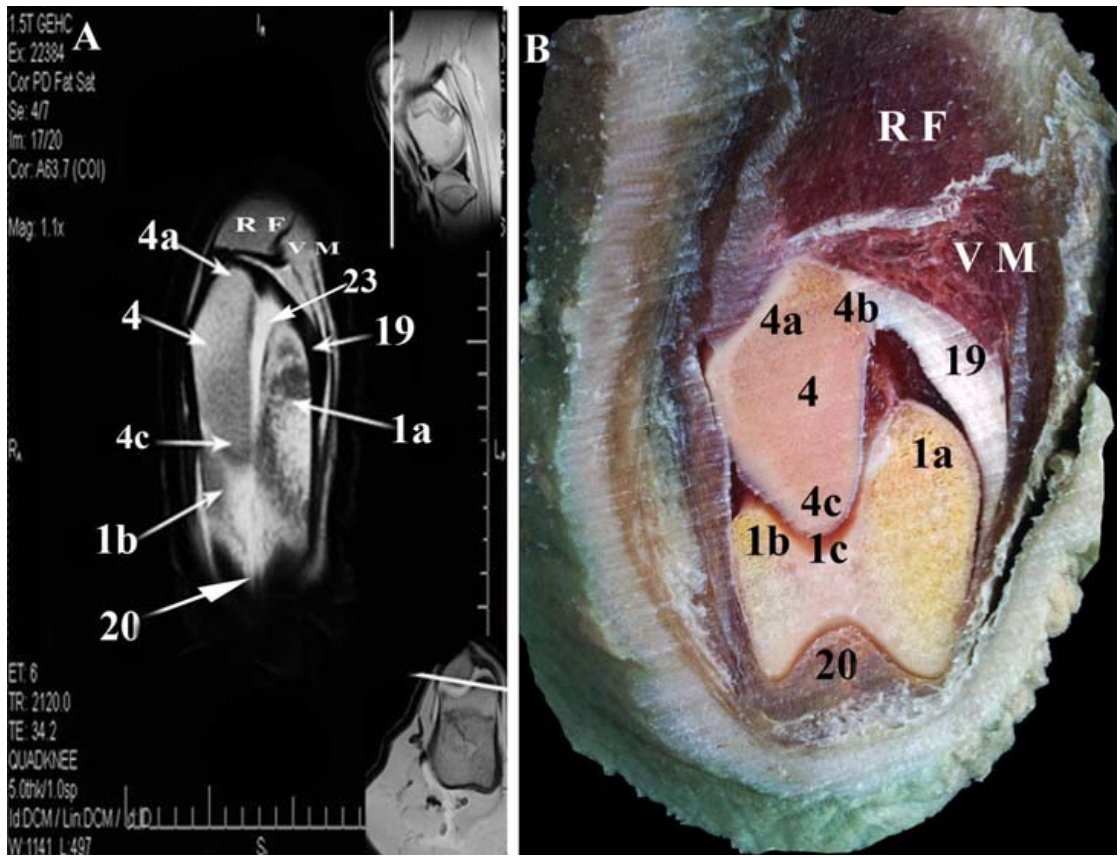

Fig. (8). Dorsal MR image (A) and gross anatomic section (B) of the left buffalo stifle $2 \mathrm{~cm}$ caudal to the most cranial part of trochleae ossis femoris (dorsal is up and lateral is to the left of the viewer). 1, Trochlea ossis femoris (1a, medial ridge; 1b, lateral ridge; 1c, intertrochlear groove); 2, Condylus medialis of os femoris; 3, Condylus lateralis of os femoris (3a, Fossa extensoria); 4, patella; (4a, Basis patellae; 4b, Processus cartilagineus; 4c, Apex patellae); 5, Condylus medialis of the tibia; 6, Condylus lateralis of the tibia; 7, Eminentia intercondylaris ( $7 \mathrm{a}$, tuberculum intercondylare mediale; $7 \mathrm{~b}$, tuberculum intercondylare laterale); 8 , Tuberositas tibiae; 10, Distal epiphysis of the femur ossification center; 11, Proximal diaphysis of the tibia ossification center; 12, lateral femorotibial sac (12a, distal pouch); 13, Meniscus lateralis; 14, Lig. Meniscofemorale; 15, Meniscus medialis (15a, caudal meniscotibial ligament); 16a, Lig. cruciatum craniale; 16b, Lig. cruciatum caudale; 17, Lig. collaterale laterlae;18, Lig. popliteum obliquum; 19, Fibrocartilagines parapatellaris medialis; 20, Lig. patellae intermedium; 21, Common tendon of the extensor digitorum longus and peronaeus tertius; 22, Popliteal artery and vein; 23, Femoropatellar joint; VM, M. vastus medialis; RF, M. rectus femoris; GL, M. gastrocnemius (Caput laterale); GM, M. gastrocnemius (Caput mediale); SDF, M. flexor digitorum superficialis; GB, M. gluteobiceps femoris.
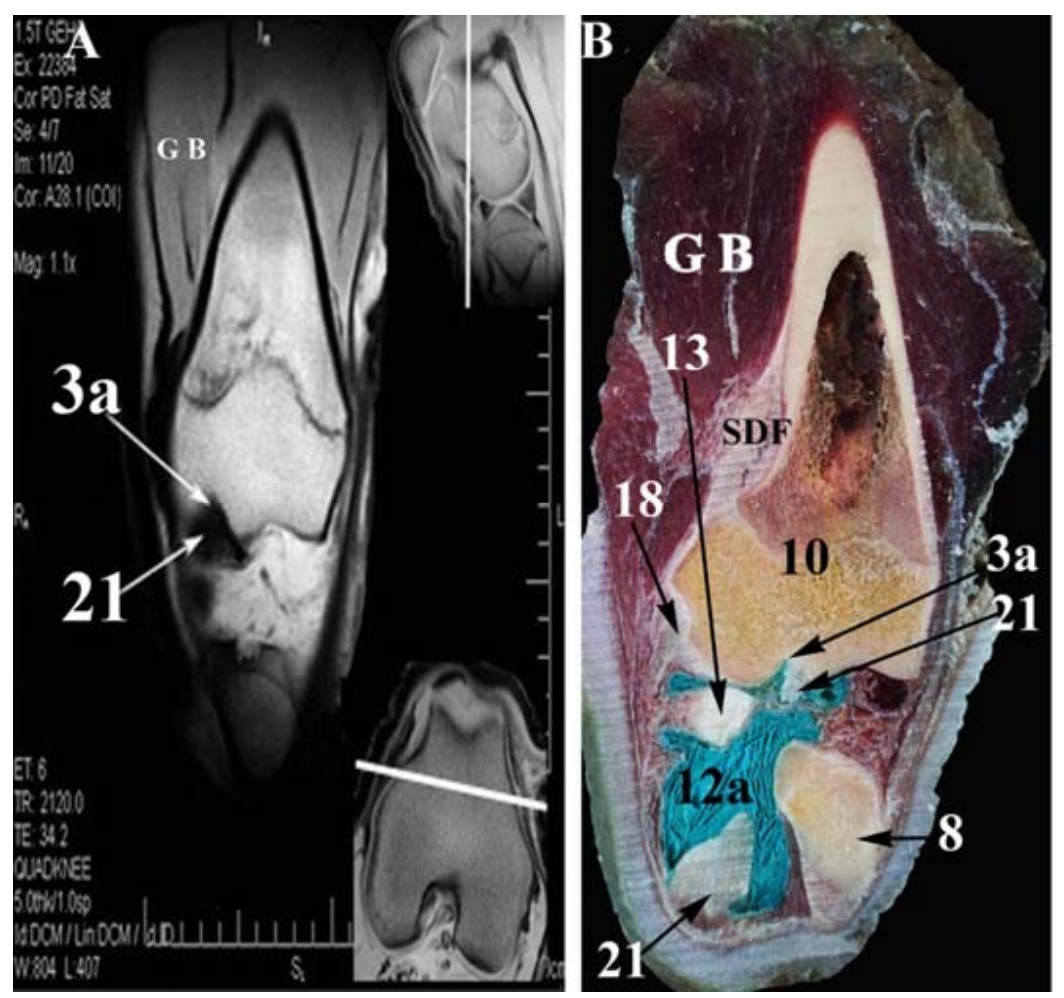

Fig. (9). Dorsal MR image (A) and gross anatomic section (B) of the left buffalo stifle at the level of the Fossa extensoria (dorsal is up and lateral is to the left of the viewer). Abbreviations as previous. 

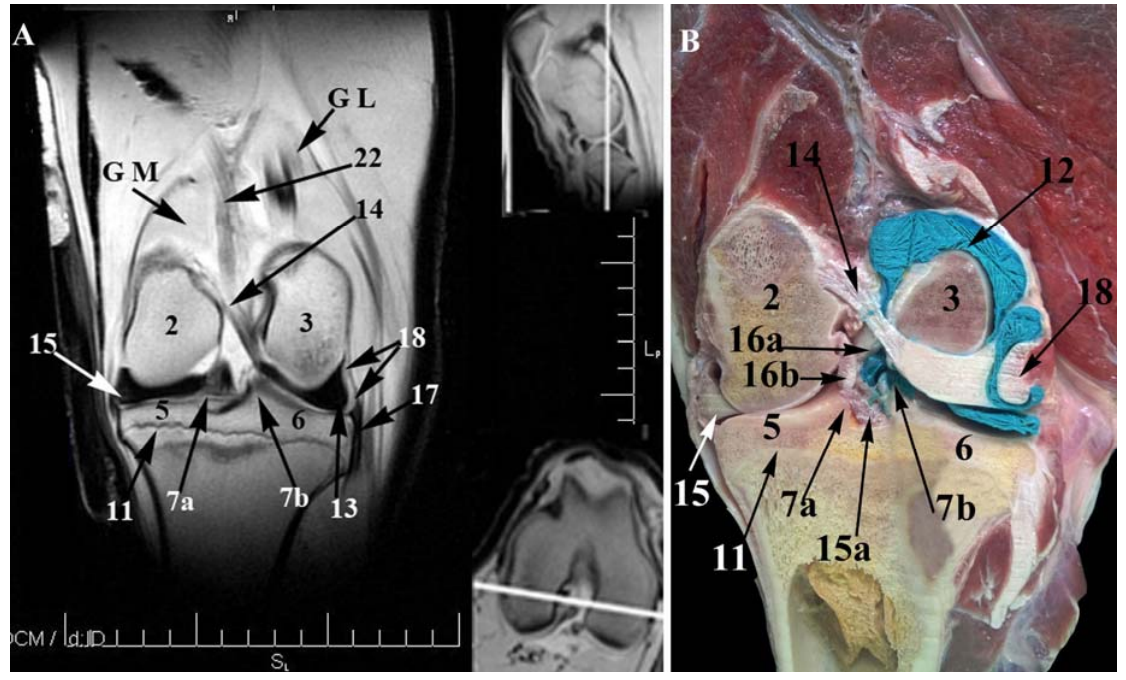

Fig. (10). Dorsal MR image (A) and gross anatomic section (B) of the buffalo right stifle at the level of the Area intercondylaris centralis (dorsal is up and lateral is to the right of the viewer). Abbreviations as previous.

The intermediate, medial and lateral patellar ligaments were recognized as hypointense signal structures converging distally. The medial and lateral femoropatellar ligaments, and the cranial and caudal meniscotibial ligaments, as well as, the meniscofemoral ligament of the lateral meniscus appeared as moderate signal intensity structures (Figs. 1, 3, 10). The cranial and caudal cruciate ligaments were recognized as moderate signal intensity bands (Fig. 7). The cranial cruciate ligament consisted of two strata; craniomedial and caudolateral. Both strata extended proximally from the medial wall of the lateral femoral condyle. The craniomedial stratum inserted in the lateral wall of the medial intercondyloid tubercle in the central intercondyloid fossa, while the caudolateral stratum ended in the central intercondyloid fossa (Fig. 6). The Caudal cruciate ligament passed medially to the cranial cruciate ligament. It extended proximally from the femoral intercondylar fossa and inserted in the popliteal notch (Fig. 7). The medial patellar fibrocartilage (Figs. 2, 3) appeared as hypointense signal structure and acted as origin for the medial patellar ligament and as insertion of the medial femoropatellar ligament.

The common tendon of Mm. extensor digitorum longus and peroneus tertius (Fig. 9) were recognized as hypointense signal structures. The infrapatellar fat body interposed between the synovial and fibrous layers of the articular capsule and occupied the space which was formed by the patella proximally, the tibial condyles distally, the femoral condyle caudally and the patellar ligaments cranially. The infrapatellar fat body separated the patellar ligament from the meniscus caudally and appeared as hyperintense signal structure so it was difficult to differentiate from the synovia because both had the same intensity (Fig. 3).

The Menisci showed very homogenous hypointensity signal in MRI and present between the femoral and tibial condyles articular cartilages to divide the medial and lateral Femorotibial joint cavities partially into two compartments for each; The Proximal sac formed between the proximal surface of the meniscus and the femoral condyle articular cartilage, while the distal sac formed between the distal surface of the meniscus and the tibial condyle articular cartilage (Figs. 1, 10). Both proximal and distal Lateral femorotibial compartments (Fig. 10) connected medially at the area between the lateral femoral and tibial condyles. The proximal and distal medial femorotibial compartments (Fig. 3) connected at the axial notched border of the medial meniscus. The proximal compartment of the medial femorotibial sac connected freely with the femoropatellar sac at the level of the ridge which was located between the medial trochlear ridge and medial femoral condyle, but at the same time, the medial and lateral femorotibial sac was separated at the level of the cruciate ligament decussating above the central tibial intercondylar fossa. The lateral meniscus didn't cover the caudolateral part of the lateral tibial condyle because that part was occupied by the tendon of origin of the M. popliteus to separate the lateral meniscus from the lateral collateral ligament. The lateral meniscus was separated from the tendon of origin of the M. popliteus by lateral Femorotibial synovial pouch that act as a bursa (Fig. 10). The tendon of origin of the M. popliteus appeared as a hypointense signal structure.

The proximal and distal femorotibial sacs appeared as a thin line of hyperintensity, proximal and distal to the lateral meniscus respectively (Figs. 1, 6, 10). The femoropatellar synovial sac appeared as hyperintense signal, as well (Fig. 3). The femoropatellar sac had a pouch which extended proximally for about $6 \mathrm{~cm}$ to form suprapatellar pouch. That pouch was separated from the overlying two portions of the M. vastus intermedius by fatty tissue.

\section{DISCUSSION}

The present study serves as primary reference that aid in MR imaging diagnosis of the buffalo stifle disorders. The knowledge of the normal cross sectional anatomy of the stifle joint in buffalo is essential for the evaluation of MRI scans. MR images in the current study provide adequate anatomical details which were compared thoroughly with the corresponding gross anatomical sections. 
Radiography has a limited capability to evaluate the soft tissue structures. Although ultrasonography provides visualization of the tendons and ligaments, it provides a limited field of imaging and each structure need to be imaged separately [16]. On the other hand, the soft tissue is difficult to be evaluated by ultrasonography as it is not possible to perform a cross sectional examination through the entire digit [17].

MRI scan is excellent imaging modality, however, its usage in veterinary medicine is limited as it is expensive and the animal should be anaesthetized [18]. Nevertheless, it has some potential advantages over the routine radiography; it provides a cross-sectional image with superior soft tissue differentiation and no superimposition of the overlying structures, which can be used for better diagnosis of abnormalities [19]. It seems that MRI scans could be beneficial if it used in large scale farms for routinely diagnosis and making-decision for surgical interventions.

The signal intensities in the cadaver specimens can be different in live animals because of the loss of fluid and blood in the cadavers, the freezing and absence of blood flow, however, the gross anatomy is the same in horses [10, 20]. There is uncertainty that it would be the same case in buffalo due to the lack of MRI scans for veterinary purpose in Egypt, therefore this research based only in specimens from the freshly slaughtered animals.

The results reveal that the compact bone appears as hypointense signal, while the spongy bone as moderate intensity structure. Such findings come in agreement with Van der Straaten et al. [10] and Holocombe et al. [21] in horses.

The articular cartilage shows hyperintensity and separate from the bone by gray line (moderate signal intensity). These results agree with Soler et al. [22] in the dog and disagree with Van der Straaten et al. [10] and Holocombe et al. [21] in the horse who recognized the articular cartilage as a layer of homogenous moderate signal intensity.

The medial and lateral menisci showed hypointense signal which was the similar to what was previously reported [10, 21-23]. However, Murray et al. [24] in the horse reported that the medial and lateral menisci ranged from moderate to low signal intensity depending on Tesla used.

The intermediate, medial and lateral patellar ligaments appeared with hypointense signal that comes parallel with the earlier results $[7,10,21,22,24]$.

The infrapatellar fat body appears as hyperintense signal so it was difficult to differentiate it with the synovial capsule because both appear with the same intensity which resemble to the past results $[21,24]$.

The medial and lateral femorotibial synovial sacs are separated at the level of the cruciate ligament decussation which agree with previous investigations [25-31] and disagree with Gad [32] in the goat who argued that both medial and lateral sacs are connected inferior to cruciate ligament decussation.

\section{CONCLUSION AND CLINICAL RELEVANCE}

The knowledge of normal anatomy of the buffalo stifle joint is necessary to provide an accurate interpretation of MR images. This study is a preliminary step toward the clinical use of MR in soft tissue injuries of the stifle in the buffalo, but more investigations may be required to evaluate the effectiveness of MRI in the diagnosis of the stifle joint diseases.

\section{CONFLICT OF INTEREST}

The authors confirm that this article content has no conflict of interest.

\section{ACKNOWLEDGEMENTS}

The authors appreciate the sincere help of Prof. Dr. Ahmed Faried, professor of human diagnostic imaging and Dr. Amr Raslan, Head of Tanta Scan diagnostic imaging laboratory, for their invaluable assistance in the practical part of this study.

\section{REFERENCES}

[1] Stark D, Bradley W. Magnetic resonance imaging. $3^{\text {rd }}$ ed. Vol. 2. St. Louis: Mosby 1999.

[2] Weaver A. Bovine medicine diseases and husbandry of cattle. In: Andrews A, Blowey R, Boyd H, Eddy R, Eds. $2^{\text {nd }}$ ed. Oxford: Blackwell Science Ltd. 2004; pp. 435-65.

[3] Shearer J, Van AS. Functional and corrective claw trimming. The veterinary clinics of North America. Food Animal Practice 2001; 171: 53-72.

[4] Kassab A, Badawi A. Ultrasonographic anatomy of the patellar ligaments: Before and after medial patellar desmotomy in buffaloes (Bos bubalis). Emir J Food Agric 2011; 23 (5): 460-5.

[5] Gehrmann S, Höhne K, Linhart W, et al. A novel interactive anatomic atlas of the hand. Clin Anat 2006; 19 (3): 258-66.

[6] Foreman J. Use of equine magnetic resonance imaging in equine lameness diagnosis. Pferdeheilkunde 1996; 12: 686-7.

[7] Gavin P, Holmes S. Stifle Joint. In: Patrick R, Gavin, Rodney S, Bagley, Eds. Practical small animal MRI. $1^{\text {st }}$ ed. Singapore: WileyBlackwell Library of Congress Cataloging-in-Publication Data 2009; pp. 233-73.

[8] Mair T, Kinns J, Jones R, Bolas N. Magnetic resonance imaging of the distal limb of the standing horse: Technique and review of 40 cases of foot lameness. Proceedings of the 49th Annual Convention of the American Association of Equine Practitioners; 2003. New Orleans, Louisiana. Equine Vet Educ 2013; 17; pp. 74-8.

[9] Cook C. MRI of the canine stifle joint. $3^{\text {rd }}$ World Veterinary Orthopaedic Congress, ESVOT-VOS 15th ESVOT Congress Bologna, Italy. 2010 Sep 15-18; University of Missouri, Columbia 2010.

[10] Van der SG, Collins S, Rijkenhuizen A, Murray R. Magnetic resonance imaging of the equine stifle: normal anatomy. (M. V. Sc. Thesis). The Netherlands: Utrecht University 2009.

[11] Nickel R, Schummer A, Seiferle E. The anatomy of domestic animals. Vol. 2. Oxford: Blackwell Science 1996.

[12] Dyce K, Sack W, Wensing C. Textbook of veterinary anatomy. $2^{\text {nd }}$ ed. Philadelphia, London, Toronto, Montreal, Sydney, Tokyo: W.B. Saunders Company 1987.

[13] Getty R. The anatomy of the domestic animals. $5^{\text {th }}$ ed. Vol. 1 Philadelphia, London, Toronto: WB Saunders Co. 1975.

[14] Schaller O. Illustrated veterinary anatomical nomenclature. Stuttgart: Enke Verlag 1992.

[15] Nomina Anatomica Veterinaria. $5^{\text {th }}$ ed. International Committee on Veterinary Gross Anatomical Nomenclature of the World Association of Veterinary Anatomists 2005. 
[16] Kaser-Hotz B, Sartoretti-Schefer S, Weiss R. Computed tomography and magnetic resonance imaging of the normal equine carpus. Vet Radiol Ultrasound 1994; 35(6): 457-61.

[17] Denoix J, Crevier N, Roger B, Lebas J. Magnetic resonance imaging of the equine foot. Vet Radiol Ultrasound 1993; 34(6): 405-11.

[18] Arencibia A, Vazquez J, Rivero M, et al. Computed tomography of normal craniocephalic structures in two horses. Anat Histol Embryol 2000; 29: 295-9.

[19] Raji A, Sardari K, Mohammadi H. Normal cross-sectional anatomy of the bovine digit: Comparison of computed tomography and limb anatomy. Anat Histol Embryol 2008; 37(3): 188-91.

[20] Carter J, Saveraid T, Rick M, Herthel D. Magnetic resonance imaging of the equine stifle. Summit in Clinical Setting. American College of Veterinary Surgeons Surgical, Chicago, Illinois 2007; pp. 17-21.

[21] Holocombe S, Bertone A, Biller D, Haider V. Magnetic resonance imaging of the equine stifle. Vet Radiol Ultrasound 1995; 36: 119-25.

[22] Soler M, Murciano J, Latorre R, Belda E, Rodri'guez M, Agut A. Ultrasonographic, computed tomographic and magnetic resonance imaging anatomy of the normal canine stifle joint. Vet J 2007; 174: 351-61.

[23] Judy C. Magnitic resonance imaging of the equine stifle. Vet Radiol Ultrasound 2011; 52: 479-84.
[24] Murray R, Werpy N, Audigié F, Denoix J, Brokken M, Schulze T. Equine MRI of the proximal tarsal region. In: Murray R, Ed. Equine MRI. West Sussex, UK: Blackwell Publishing Ltd. 2011; pp. 421-7.

[25] Ibrahim I, Moustafa M. Some anatomical observation on the stifle joint of the buffalo in Egypt. Vet Med J Cairo University 1977; 23(4): 123-32.

[26] Elhanbaly R. Why the Incidence of the upward fixation of the patella is higher in Buffalo than in Cattle? M. V. Sc. Thesis. Egypt: Assiut University 2011.

[27] Skerrit G, McLelland J. An introduction to the functional anatomy of the limbs of the domestic animals. Bristol, England: John Wright \& Sons 1984.

[28] De Lahunta A, Habel R. Applied veterinary anatomy. Philadelphia, London, Toronto, Mexico City, Rio de Janeiro, Sydney, Tokyo, Hong Kong: Library of Congress Cataloging in Publication Data 1986.

[29] Konig H, Liebich H. Veterinary Anatomy of Domestic Mammals. Stuttgart, Germany: Schattauer GmbH, Holderlinestrabe 2004.

[30] Budras K, Sack W, Rock S. Anatomy of the Horse. $5^{\text {th }}$ ed. Hannover-Germany: Schlütersche Verlagsgesellschaft $\mathrm{mbH} \&$ Co. KG., Hans-Böckler-Alle 2009.

[31] Miller M, Chrisetensen G, Evans H. Anatomy of the Dog. Philadelphia. London: W.B Saunders Company 1979.

[32] Gad M. Some anatomical studies on the Genual Articulation of the Goat. M. V. Sc, Thesis. Egypt: Cairo University 1979. 